\title{
Host Alternative NADH:Ubiquinone Oxidoreductase Serves as a Susceptibility Factor to Promote Pathogenesis of Rhizoctonia solani in Plants
}

\author{
Ravi Kant, Kriti Tyagi, Srayan Ghosh, and Gopaljee Jha ${ }^{\dagger}$ \\ Plant Microbe Interactions Laboratory, National Institute of Plant Genome Research, Aruna Asaf Ali Marg, New Delhi 110067, India \\ Accepted for publication 6 June 2019.
}

\begin{abstract}
Phytopathogens have evolved mechanisms to utilize host genes (commonly known as susceptibility factors) to promote their pathogenesis. Rhizoctonia solani is a highly destructive fungal pathogen of various plants, including rice. We previously reported rice genes that were differentially regulated during $R$. solani pathogenesis. In this study, we analyzed the role of tomato homologs of two rice genes, isoflavone reductase (IFR) and alternative NADH:ubiquinone oxidoreductase $(N U O R)$, as potential susceptibility factors for $R$. solani. Virus-induced gene silencing of NUOR in tomato resulted in compromised susceptibility against $R$. solani, whereas

$I F R$-silenced plants demonstrated susceptibility similar to that of control plants. NUOR silencing in tomato led to homogenous accumulation of reactive oxygen species (optimum range) upon $R$. solani infection. In addition, the expression and enzyme activity of some host defense and antioxidant genes was enhanced, whereas $\mathrm{H}_{2} \mathrm{O}_{2}$ content, lipid peroxidation, and electrolyte leakage were reduced in NUOR-silenced plants. Similarly, transient silencing of $O S N U O R$ provided tolerance against $R$. solani infection in rice. Overall, the data presented in this study suggest that NUOR serves as a host susceptibility factor to promote $R$. solani pathogenesis.
\end{abstract}

Rhizoctonia solani is a soilborne necrotrophic fungal pathogen that causes catastrophic diseases in numerous plant species (Anderson et al. 2017; Ghosh et al. 2014; Pan et al. 1999; Zou et al. 2000). Extensive polymorphism in different strains enables $R$. solani to adopt diverse mechanisms to infect various hosts (Ghosh et al. 2019; Kuramae et al. 2003; Xia et al. 2017). R. solani accounts for great loss in crop yield and thereby poses a significant threat to socio-economic development. The practical solution to control this pathogen relies mainly on cultural practices and adoption of fungicides. Because of its complex lifestyle, coenocytic nature and despite significant efforts, understanding of $R$. solani remains elusive. Hence, developing resistance against this pathogen is a challenging task (Channamallikarjuna et al. 2009; Srinivasachary et al. 2011).

Plants have evolved strong defense responses in order to develop resistance against phytopathogens (Jones and Dangl 2006). However, the continuing arms race between plants and pathogens has led to the evolution of some pathogens that overcome plant defense responses (Engelhardt et al. 2018). Manipulation of host cell physiology has been used as a strategy by phytopathogens to promote susceptibility (Dobón et al. 2015; Schnepf et al. 2018). The host genes that promote disease susceptibility are referred to as susceptibility genes (S-genes) or factors. However, knowledge about how S-genes facilitate pathogen growth and infectivity is still

${ }^{\dagger}$ Corresponding author: G. Jha; jmsgopal@nipgr.ac.in or jmsgopal@gmail.com

Funding: This work was supported by a core research grant from the National Institute of Plant Genome Research, India and research funding from the Government of India Department of Biotechnology. R. Kant is supported by a national postdoctoral fellowship from the Science and Engineering Research Board of the Government of India Department of Science and Technology, K. Tyagi is supported by a senior research fellowship from the Government of India Department of Biotechnology, and S. Ghosh is supported by an Shyama Prasad Mukherjee fellowship from the Government of India Council of Scientific and Industrial Research.

*The $\boldsymbol{e}$-Xtra logo stands for "electronic extra" and indicates that four supplementary figures and three supplementary tables are published online.

The author(s) declare no conflict of interest.

(c) 2019 The American Phytopathological Society limited. One of the well-known examples of S-genes includes Mildew resistance locus o (Mlo) in barley. Loss-of-function mutation or RNAi-mediated silencing of Mlo genes provides broad-spectrum resistance against powdery mildew fungi in a wide range of plant species (Kusch and Panstruga 2017). Host gene expression profiling has been used as an effective method for identification of S-genes in plants (Hok et al. 2011; Santos et al. 2017). Downregulation of S-genes could play a pivotal role in compromising susceptibility against pathogens and thereby enhancing plant disease resistance.

We previously reported rice genes that were differentially regulated upon $R$. solani infection (Ghosh et al. 2017). Based on the contrasting expression dynamics of these genes in susceptible (PB1 and TP309) and partially resistant (TETEP) rice genotypes, we selected isoflavone reductase (IFR) and alternative NADH: ubiquinone oxidoreductase (an alternative oxidoreductase, abbreviated here as $N U O R$ ) as putative $\mathrm{S}$-genes in this study. IFR is a crucial enzyme for isoflavonoid phytoalexin biosynthesis in plants and plays a major role in several biotic and abiotic stresses (Cheng et al. 2015; Kim et al. 2010). NUORs are mitochondrial components (single subunit enzymes) in plants involved in the electron transport chain (ETC) pathway. This gene also regulates metabolic homeostasis and gene expression for controlling various biotic and abiotic stresses (Kerscher 2000; Saha et al. 2016; Schertl and Braun 2014). Reports show the importance of mitochondrial components in controlling reactive oxygen species (ROS) accumulation during stress responses in Arabidopsis and tobacco (Cvetkovska et al. 2014; Moller 2001; Wu et al. 2015).

To validate the role of IFR and NUOR as putative S-genes, we adopted a gene silencing approach. Our data suggest that silencing of the NUOR gene compromises the pathogenesis of $R$. solani in tomato and rice. Furthermore, molecular and biochemical assays suggested that the silencing of NUOR could enhance host defense responses and promote homeostasis of ROS during $R$. solani infection.

\section{MATERIALS AND METHODS}

Identification and selection of putative S-genes. We previously reported rice genes that were commonly differentially regulated in two different susceptible rice genotypes (PB1 and TP309) upon $R$. solani infection (Ghosh et al. 2017). In addition, we 
analyzed the expression dynamics of these genes in $R$. solaniinfected TETEP, a partially resistant rice cultivar (BioProject ID: PRJNA298635). We selected genes that were more than 2.5-fold upregulated in susceptible cultivars (PB1 and TP309) but downregulated or not expressed in partially resistant rice (TETEP) as candidate S-genes (Supplementary Table S1). Based on expression dynamics, two genes-namely OSIFR (LOC_Os01g13610.1) and OsNUOR (LOC_Os07g37730.1)—were selected as putative $\mathrm{S}$-genes in rice. Furthermore, the tomato orthologs of IFR and NUOR were identified by the BLASTx tool using the rice gene sequence as input. Induction of these genes in $R$. solani-infected plants (rice and tomato) was also validated by quantitative reverse transcription PCR (RT-qPCR).

Construction of recombinant vectors. The tobacco rattle virus plasmid (pTRV) vector was used to generate all recombinant clones for virus-induced gene silencing (VIGS) in tomato (Liu et al. 2002). Phytoene desaturase (PDS), which is a reporter gene responsible for carotenoid biosynthesis in plants and leads to the photobleaching phenotype in leaves upon gene silencing, was used as a positive control during the analysis (Benedito et al. 2004). For construction of recombinant pTRV2 vectors, the partial 374-bp fragment of $P D S$ (accession NM_001247166.2), 569 bp of IFR (accession XM_ 004248665), and 513 bp of NUOR (accession XM_004232770) were PCR amplified from tomato cDNA using gene-specific primers with the XbaI/SacI restriction enzymes (Supplementary Tables S2 and S3) and cloned in the pJET1.2 cloning vector (Thermo Scientific). Thereafter, the target gene fragments were subcloned into the pTRV2 vector at the $\mathrm{XbaI} / \mathrm{SacI}$ restriction sites in the antisense orientation. All of the vectors, pTRV1, pTRV2, and recombinant pTRV2 plasmids (pTRV2:PDS, pTRV2:IFR, and pTRV2:NUOR) were mobilized individually into Agrobacterium strain GV3101.

To construct the OsNUOR RNAi clone, the 345-bp fragment of OsNUOR was PCR amplified from rice cDNA and cloned in the sense and antisense orientation in a modified pGEMT vector containing an intron at the $\mathrm{SphI} / \mathrm{NcoI}$ and PstI/NdeI restriction enzymes, respectively. In addition, the sense-intron-antisense cassette was subcloned into the pBI121 vector at the BamHI/SacI sites to generate a hairpin RNAi clone (pBI121:hp-OsNUOR). The constructs were mobilized into Agrobacterium strain LBA4404 for further study.

Gene silencing in tomato. Tomato seedlings at the four-leaf stage were used for the agroinfiltration assay. The primary culture of each Agrobacterium cell harboring a specific plasmid (pTRV1/ pTRV2:0/pTRV2:PDS/pTRV2:IFR/pTRV2:NUOR) was grown in Luria-Bertani (LB) medium supplemented with rifampicin (50 $\mathrm{mg} / \mathrm{ml})$ and kanamycin $(50 \mathrm{mg} / \mathrm{ml})$ at $28^{\circ} \mathrm{C}$ in a 150 -rpm incubator shaker overnight. In addition, a secondary culture was grown using $0.1 \%$ of the primary culture as inoculum and the bacterial cells were pelleted down by centrifugation at $5,000 \mathrm{rpm}$ for $5 \mathrm{~min}$. The bacterial pellet was resuspended in induction buffer $(10 \mathrm{mM}$ of $\mathrm{MgCl}_{2}, 10 \mathrm{mM}$ of MES[2-(N-morpholino) ethane sulfonic acid], and $200 \mu \mathrm{M}$ of acetosyringone) keeping the $\mathrm{OD}_{600}=1.0$ and incubated at $25^{\circ} \mathrm{C}$ for $2 \mathrm{~h}$ with gentle shaking. Agrobacterium suspension with the specific pTRV2 plasmid (empty as well recombinants) was mixed with cells of the pTRV1 plasmid in a 1:1 ratio. Each mixture was infiltrated on the abaxial side of tomato seedlings ( $\sim 10$ days old) using a 1-ml needleless syringe and incubated in a growth chamber (Percival Scientific Inc.) at $25^{\circ} \mathrm{C}$ and $80 \%$ RH with 16-h/8-h day/night conditions (Liu et al. 2002). Each experiment was repeated three times with a minimum of 10 tomato seedlings per gene construct per repeat.

Gene silencing in rice. For transient agroinfiltration in rice, 30- to 45-day-old rice plants grown under control growth conditions $\left(28^{\circ} \mathrm{C} ; 80 \% \mathrm{RH}\right.$ and $16-\mathrm{h} / 8$-h day/night conditions) were used. Agrobacterium strain LBA4404 harboring pBI121:0 (vector control) and pBI121:hp-OsNUOR was grown in LB medium supplemented with rifampicin $(50 \mathrm{mg} / \mathrm{ml})$ and kanamycin $(50 \mathrm{mg} / \mathrm{ml})$ at $28^{\circ} \mathrm{C} / 150 \mathrm{rpm}$ overnight. The Agrobacterium cells were pelleted and resuspended in induction buffer as described above and inoculated in the midvein of rice leaves using a syringe, per the method described by Jha et al. (2007). Each experiment was repeated three times with four to five leaves infiltrated per construct and a minimum of four to five plants per construct per repeat.

Semiquantitative PCR and qPCR for gene expression studies. Total RNA was isolated from $200 \mathrm{mg}$ of harvested leaf tissues using the RNeasy Plant Mini Kit (Qiagen) per the manufacturer's instructions and was quantified using a NanoDrop spectrophotometer (Thermo Scientific). Two micrograms of RNA was used for cDNA synthesis using a high-capacity cDNA synthesis kit (Applied Biosystems). Transcript accumulation of target genes was estimated by semiquantitative PCR (RT-PCR) using $2 \mu \mathrm{l}$ of 4-fold diluted cDNA as a template. DyNAzyme II Taq polymerase (Thermo Scientific) was used for RT-PCR with initial denaturation at $95^{\circ} \mathrm{C}$ for $3 \mathrm{~min}, 28$ cycles at $95^{\circ} \mathrm{C}$ for $30 \mathrm{~s}$, annealing at $55^{\circ} \mathrm{C}$ for $30 \mathrm{~s}$, and extension at $72^{\circ} \mathrm{C}$ for $30 \mathrm{~s}$. The tomato actin gene was utilized as an endogenous control in each case.

The transcript level of target genes was determined through RTqPCR using gene-specific primers and PowerUp SYBR Green Master Mix (Applied Biosystems) and $2 \mu \mathrm{l}$ of 4 -fold diluted cDNA from corresponding plant samples as the template. Actin (for tomato) and $18 \mathrm{~S}$ (for rice) genes were used to normalize the gene expression. The relative expression of target genes in test plants was determined using the comparative $\mathrm{D}$ cycle threshold $(\mathrm{Ct})$ method $2^{-\Delta \mathrm{Ct}}$ and fold change in expression was calculated using the $2^{-\Delta \Delta \mathrm{Ct}}$ method over control plants (Livak and Schmittgen 2001; Schmittgen and Livak 2008). Each experiment was repeated thrice with three technical and three biological replicates.

$\boldsymbol{R}$. solani infection assay. The equal-sized sclerotia of the $R$. solani AG1-IA strain (BRS1) were collected from potato dextrose agar plates (HiMedia) at $28^{\circ} \mathrm{C}$ and were used to infect rice (Oryza sativa L. 'PB1') and tomato (Solanum lycopersicum 'Pusa Ruby').

For tomato infection, each sclerotium was attached on the abaxial side of young leaves by clipping tiny strips of aluminum foil. The infected plants were incubated in growth chambers preset at $28^{\circ} \mathrm{C}$ and $80 \%$ RH. A minimum of 10 plants per construct with at least two leaves per plant were infected with $R$. solani per experiment and at least three independent experiments were conducted during the study. Fungal pathogenicity in infected leaves was measured in terms of the extent of disease symptoms produced in each of the treated leaves. Thereafter, we developed a disease scale based on the severity of observed disease symptoms as follows: NS, no symptoms; mild, a few tiny necrotic spots; medium, fusion of tiny necrotic spots into large spots; and severe, fusion of many large necrotic spots and cell death. The estimated relative disease index in silenced and vector control plants at 3 and 7 days after $R$. solani infection was represented as a bar chart.

The sclerotium was attached inside tillers of the sheaths in order to infect rice, as described in Ghosh et al. (2017). A minimum of four to five different rice plants and four to five tillers per plant infected with $R$. solani were used during the analysis. The disease severity index was estimated by calculating the percentage of relative vertical sheath colonization (RVSC), as described by Ghosh et al. (2017). The experiment was independently repeated three times. The samples were harvested from the infected leaves/tillers and were used for detailed biochemical and molecular analysis.

Pathogen load quantification. $R$. solani biomass in infiltrated tomato plants was quantified by analyzing the abundance of its $18 \mathrm{~S}$ rRNA using RT-qPCR. Expression was normalized using the tomato actin gene. Each experiment was repeated three times with three technical and biological replicates.

ROS accumulation (3,3'-diaminobenzidine staining). ROS accumulation was estimated by the 3,3'-diaminobenzidine (DAB) immunohistochemical staining method (Ghosh et al. 2017). $R$. solani-infected tomato leaves and rice sheaths were stained using $1 \mathrm{mg} / \mathrm{ml}$ of DAB solution (prepared in $50 \mathrm{mM}$ of Tris acetate buffer, $\mathrm{pH}$ 5.0) and incubated in the dark at $25^{\circ} \mathrm{C}$ for $16 \mathrm{~h}$ with gentle 
shaking. A mixture of ethanol/acetone (3:1 ratio) was used for destaining the leaves in a boiling water bath for $1 \mathrm{~h}$, which resulted in the appearance of brown color patches in leaves/sheaths as a result of oxidation of $\mathrm{DAB}$ by $\mathrm{H}_{2} \mathrm{O}_{2}$. Images were captured using a digital camera (DS-Rs1; Nikon). The experiment was repeated three times with a minimum of 10 leaves/sheaths analyzed per treatment during each repeat.

$\mathrm{H}_{2} \mathrm{O}_{2}$ quantification. $\mathrm{H}_{2} \mathrm{O}_{2}$ quantification was performed in $R$. solani-infected tomato plants (agroinfiltrated with pTRV plasmids pTRV:0 and pTRV:NUOR) as described by Velikova et al. (2000). Infected leaf tissue $(0.5 \mathrm{~g})$ was homogenized and mixed in $2.0 \mathrm{ml}$ of $0.1 \%$ (wt/vol) trichloroacetic acid (TCA) and centrifuged at $13,000 \mathrm{rpm}$ for $10 \mathrm{~min}$. The supernatant obtained was mixed with $1 \mathrm{ml}$ of $10 \mathrm{mM}$ potassium phosphate buffer $(\mathrm{pH} \mathrm{7.0)}$ and $1 \mathrm{ml}$ of potassium iodide solution. After $10 \mathrm{~min}$ of incubation, spectrophotometric measurement at $390 \mathrm{~nm}$ was carried out. The $\mathrm{H}_{2} \mathrm{O}_{2}$ concentration (in nanomoles per gram of fresh weight) was determined using a standard curve. The experiment was repeated three times with a minimum of 10 leaves analyzed per treatment during each repeat.

Lipid peroxidation (malondialdehyde) assay. A previously reported protocol for measuring malondialdehyde (MDA) content, a marker of lipid peroxidation, was followed (Hodges et al. 1999) with a few modifications. The emerging leaf samples from tomato plants $(200 \mathrm{mg})$ were harvested, homogenized into a fine powder using a mortar and pestle, and mixed with $4 \mathrm{ml}$ of $0.1 \%$ TCA. After vortexing and centrifugation at $8,000 \times g$ for $15 \mathrm{~min}, 1 \mathrm{ml}$ of the supernatant was mixed with $2 \mathrm{ml}$ of the solution of $20 \%$ TCA and $0.5 \%$ 2-thiobarbituric acid. The mixture was heated at $95^{\circ} \mathrm{C}$ for $30 \mathrm{~min}$, followed by cooling on ice, and absorbance was recorded at 450, 532, and $600 \mathrm{~nm}$ using a spectrophotometer (BMG Labtech). The MDA concentration was calculated using the following formula: MDA concentration (in micromoles/liter) $=6.45 \times$ $\left(\mathrm{OD}_{532}-\mathrm{OD}_{600}\right)-0.56 \times \mathrm{OD}_{450}$. The experiment was repeated three times with a minimum of 10 leaves analyzed per treatment during each repeat.

Electrolyte leakage assay. To determine electrolyte leakage in tomato leaves, we followed a previously reported method (Kang et al. 2009) with slight modifications. Leaf discs (5 mm in diameter) from $R$. solani-infected pTRV:0 and pTRV:NUOR infiltrated plants were collected and incubated in $15 \mathrm{ml}$ of deionized water for $4 \mathrm{~h}$ in a glass test tube at $25^{\circ} \mathrm{C}$ (for diffusion of solutes in water). The conductivity of each sample at 1,2 , and 3 days postinoculation (dpi) was recorded using a conductivity meter (LABMAN Scientific Instruments Pvt. Ltd.). To estimate total electrolyte leakage, samples were autoclaved at $121^{\circ} \mathrm{C}$ for $15 \mathrm{~min}$ and conductivity was again recorded after all tubes were cooled to $25^{\circ} \mathrm{C}$. Electrolyte leakage was measured using the following formula: Percentage electrolyte leakage $=$ (Conductivity of initial electrolyte leakage/ conductivity of total electrolyte leakage) $\times 100$. The experiment was repeated three times with a minimum of 10 leaves analyzed per treatment during each repeat.

Antioxidant activity assays. The following enzymatic assays were performed to determine the antioxidant activity in pTRV infiltrated tomato plants.

Catalase activity. To estimate catalase (CAT) activity, $0.5 \mathrm{~g}$ of leaf sample was homogenized with $2.0 \mathrm{ml}$ of extraction buffer (100 mM of potassium phosphate buffer, $\mathrm{pH} 7.0,1.0 \%$ polyvinyl pyrrolidone [PVP], and $0.5 \mathrm{mM}$ EDTA). Upon centrifugation at $13,000 \mathrm{rpm}$ for $10 \mathrm{~min}$ at $4^{\circ} \mathrm{C}, 0.2 \mathrm{ml}$ of the supernatant (enzyme extract) was mixed with $100 \mathrm{mM}$ of phosphate buffer (pH 7.0) and $12.5 \mathrm{mM}$ of $\mathrm{H}_{2} \mathrm{O}_{2}$ in $2 \mathrm{ml}$ of reaction solution. The change in absorbance $\left(\mathrm{A}_{240}\right)$ was monitored spectrophotometrically for $2 \mathrm{~min}$ compared with the control. Enzyme activity was calculated as micromoles of $\mathrm{H}_{2} \mathrm{O}_{2}$ per milligram of protein per minute by measuring the decrease in absorbance attributable to $\mathrm{H}_{2} \mathrm{O}_{2}$ dissociation using the coefficient of absorbance, $\xi=39.4 / \mathrm{mM} / \mathrm{cm}$ (Azevedo et al. 1998).
Superoxide dismutase activity. Plant leaf samples (0.2 g) were homogenized in $1 \mathrm{ml}$ of $100 \mathrm{mM}$ phosphate buffer ( $\mathrm{pH} 7.0$ ) in order to estimate superoxide dismutase (SOD) activity. Upon centrifugation at 13,000 rpm for $10 \mathrm{~min}$, the supernatant was collected and mixed with $2 \mathrm{ml}$ of a reaction solution $(100 \mathrm{mM}$ of potassium phosphate, $\mathrm{pH} 7.8,75 \mu \mathrm{M}$ of nitroblue tetrazolium, $20 \mathrm{mM}$ of methionine, $50 \mu \mathrm{M}$ of riboflavin, and $0.1 \mathrm{mM}$ of EDTA). The reaction mixture was incubated at $28^{\circ} \mathrm{C}$ for $10 \mathrm{~min}$. Absorbance at $560 \mathrm{~nm}$ was measured using a spectrophotometer to determine SOD activity denoted as units per milligram of protein (Giannopolitis and Ries 1977).

Ascorbate peroxidase activity. To estimate ascorbate peroxidase (APX) activity, $0.2 \mathrm{~g}$ of leaf sample from tomato plants was homogenized in $1 \mathrm{ml}$ of extraction buffer $(100 \mathrm{mM}$ of potassium phosphate buffer, $\mathrm{pH} 7.0,1.0 \% \mathrm{PVP}$, and $0.5 \mathrm{mM}$ of EDTA). Upon centrifugation at $13,000 \mathrm{rpm}$ for $10 \mathrm{~min}$ at $4^{\circ} \mathrm{C}, 0.2 \mathrm{ml}$ of the supernatant (enzyme extract) of each sample was added to the reaction solution $(100 \mathrm{mM}$ of potassium phosphate buffer, $\mathrm{pH} 7.0$, $1.0 \mathrm{mM}$ of ascorbic acid, and $0.25 \mathrm{mM}$ of $\mathrm{H}_{2} \mathrm{O}_{2}$ ). The reaction mixture was incubated at $28^{\circ} \mathrm{C}$ for $10 \mathrm{~min}$ and absorbance was measured at $290 \mathrm{~nm}$. APX activity was calculated using the molar extinction coefficient, $\xi=2.8 / \mathrm{mM} / \mathrm{cm}$, and unit activity was expressed as micromoles of ascorbic acid oxidized per milligram of protein per minute (Nakano and Asada 1981).

\section{RESULTS}

Selecting putative $S$-genes from interaction transcriptome data. RNA sequencing analysis of $R$. solani-infected rice leaves revealed that several genes were commonly upregulated in two different susceptible rice cultivars (PB1 and TP309) during $R$. solani pathogenesis (Ghosh et al. 2017). Among these genes, we observed some to be highly upregulated ( $>2.5$-fold) in susceptible cultivars but downregulated and/or minimally expressed in the partially tolerant cultivar, TETEP. We selected two such genes (OSIFR and $O S N U O R$ ) as potential S-genes for further characterization. Using RT-qPCR, we observed that OsIFR and $O S N U O R$ (Fig. 1A and $\mathrm{B}$ ) were significantly upregulated during $R$. solani infection in PB1. However, expression of these genes was significantly downregulated in $R$. solani-infected TETEP at 3 dpi (Supplementary Fig. S1).

Generally, the transient gene silencing approach has its own limitations (e.g., gene silencing efficiency, duration of silencing) in monocots (Scofield and Nelson 2009). However, the VIGS approach has been widely used to silence genes in various plants, including tomato (Senthil-Kumar and Mysore 2011, 2014). Previous studies showed that $R$. solani strains belonging to different anastomosis groups can naturally infect and establish disease in tomato (Misawa and Kuninaga 2010; Taheri and Tarighi 2012). In this study, we observed that the $R$. solani AG1-IA strain (BRS1) infects and causes disease in tomato under laboratory as well as greenhouse conditions. Thus, we employed Tobacco rattle virus (TRV)-mediated VIGS for functional characterization of putative $\mathrm{S}$-genes in tomato. The tomato orthologs of OSIFR (accession $\mathrm{XP}_{-}$ 004248713.1; identity: 40\%) and OSNUOR (accession XP_ 004232818.1; identity: 76\%) were identified using the BLASTx tool. Using RT-qPCR, we observed both IFR and NUOR (Fig. 1C and D) to be upregulated upon $R$. solani infection in tomato.

VIGS-mediated silencing of putative $S$-genes in tomato. TRV-VIGS-mediated silencing was carried out to characterize IFR and NUOR as potential S-genes against $R$. solani. The tomato seedlings were agroinfiltrated with pTRV:0 (vector control), pTRV: PDS (positive control), pTRV:IFR, and pTRV:NUOR. The photobleaching phenotype in emerging leaves of pTRV:PDS infiltrated plants indicated silencing of the PDS gene. On the other hand, no visual silencing phenotype was observed in the case of pTRV:0, pTRV:IFR, and pTRV:NUOR infiltrated plants (Fig. 2A). Furthermore, semiquantitative PCR and RT-qPCR analysis (Fig. 2B and C) 
confirmed a significant decrease in the transcript level of targeted endogenous genes (PDS, IFR, and NUOR) in the respective VIGS plants compared with the empty vector (pTRV:0) infiltrated plants.

$\boldsymbol{R}$. solani pathogenesis in silenced tomato. We analyzed whether silencing of IFR and NUOR compromises the pathogenesis of $R$. solani in tomato. $R$. solani-infected leaves showed severe necrotic lesions in the pTRV:0 and pTRV:IFR infiltrated plants at $3 \mathrm{dpi}$, whereas minute necrotic lesions were observed in the infected leaves of pTRV:NUOR plants (Fig. 3A). By 7 dpi, the infection proceeded to other healthy leaves in the twigs of pTRV: 0 and pTRV:IFR infiltrated plants. However, only the inoculated leaves showed necrotic symptoms and there was only limited spread of the disease to the other leaves in the twigs of pTRV:NUOR infiltrated plants (Fig. 3B). RT-qPCR analysis revealed downregulated expression of $I F R$ and NUOR in $R$. solani-infected leaves (3 dpi) of pTRV:IFR and pTRV:NUOR infiltrated plants, respectively (Fig. 3C). Because the primary infected leaves of pTRV infiltrated plants were completely necrotic and mostly degenerated at $7 \mathrm{dpi}$, we analyzed the expression of IFR and NUOR genes in the twigs. As shown in Figure 3D, we observed sustained silencing of these genes in $R$. solani-infected twigs at $7 \mathrm{dpi}$. We further monitored the abundance of $R$. solani $18 \mathrm{~S}$ rRNA in the primary infected leaves at $3 \mathrm{dpi}$ and in the twigs at 7 dpi to quantify the pathogen load. The pathogen load was significantly high in pTRV: 0 and pTRV:IFR infiltrated plants, whereas pTRV:NUOR infiltrated plants exhibited a significantly reduced pathogen load at 3 and 7 dpi
(Fig. 3E and F). Overall, this suggested that NUOR silencing confers tolerance against $R$. solani infection in tomato. The disease index categorizing observed disease symptoms as mild, medium, and severe in pTRV:NUOR and pTRV:0 plants further supported enhanced tolerance in the NUOR-silenced plants (Supplementary Fig. S2).

NUOR silencing modulates ROS homeostasis and expression of mitochondrial genes in tomato. NUOR is known to function as an additional electron entry and as an exit point in the mitochondrial ETC pathway in plants (Kerscher 2000). A recent study demonstrated that defects in the ETC pathway (mitochondrial complex I) cause induced accumulation of ROS in Arabidopsis (Soto et al. 2015). Interestingly, the emerging leaves of NUORsilenced tomato plants showed enhanced ROS accumulation compared with that of pTRV:0, pTRV:PDS, and pTRV:IFR plants (Fig. 4A).

We further tested whether NUOR silencing modulates other components of the mitochondrial complex system, which can influence ROS homoeostasis and defense. Based on previous studies (Meyer et al. 2009; Wu et al. 2015), we selected tomato orthologs of Arabidopsis genes (NDUFA5, NDUFA9, NDUFS1, NDUFS4, NDUFS8, NDUFV1, CA2, SOM42, NAD1a, and NAD3) encoding mitochondrial components to study alteration in their expression during NUOR silencing in tomato. Quantitative expression analysis revealed only NDUFS1 and NAD3 to be induced in pTRV:NUOR plants compared with vector control

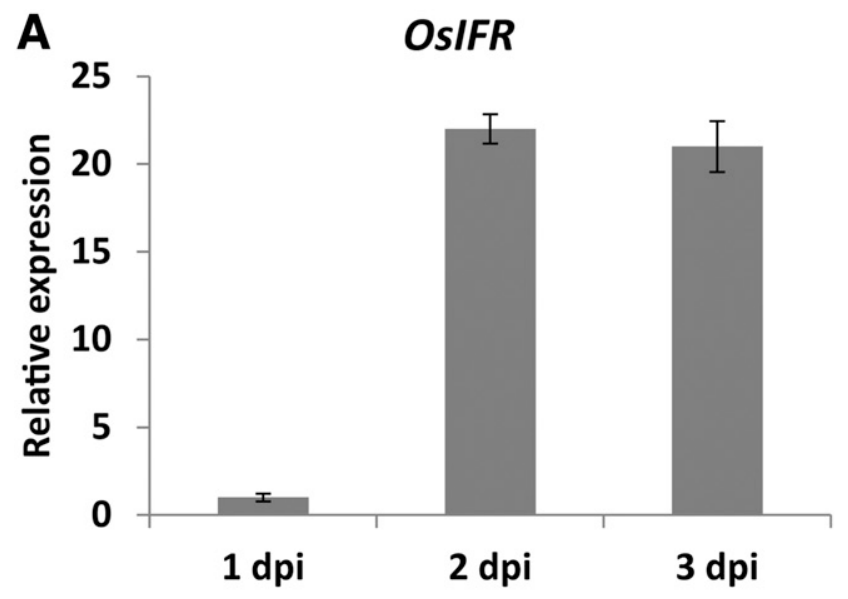

B

\section{OsNUOR}

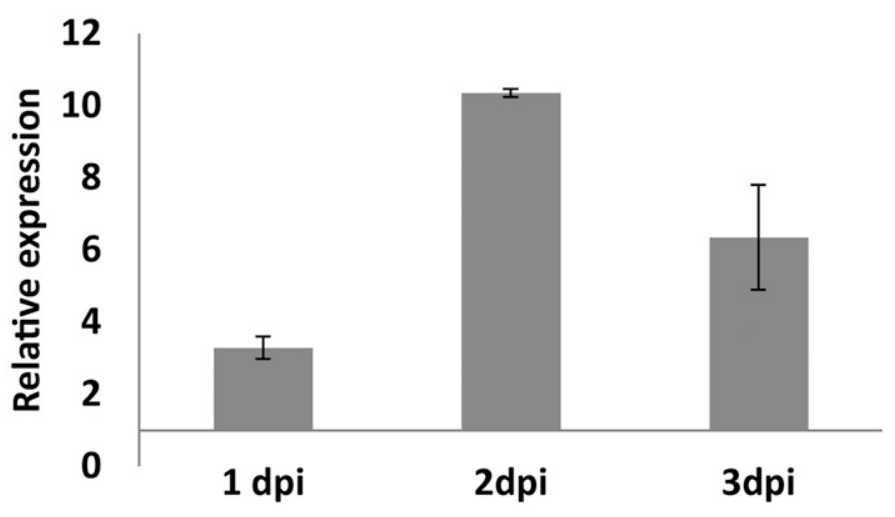

C

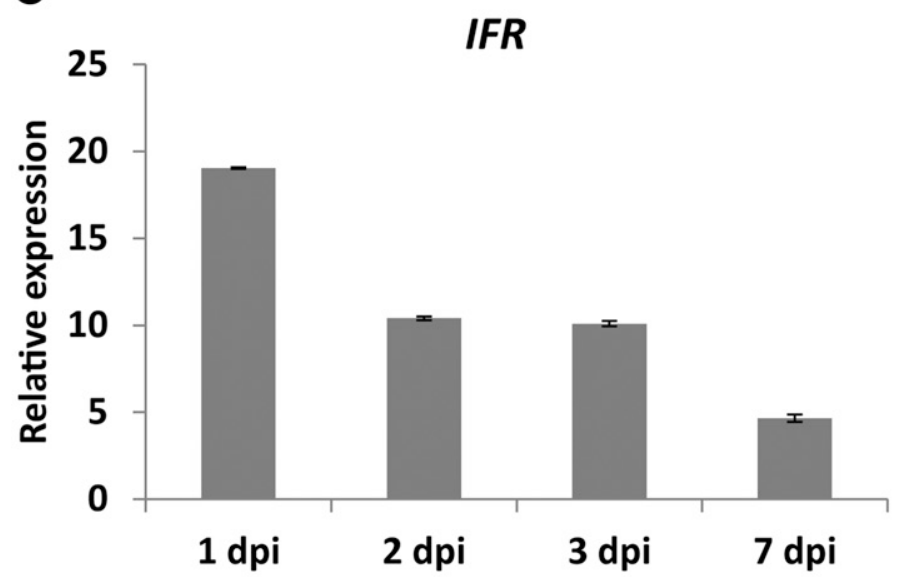

D

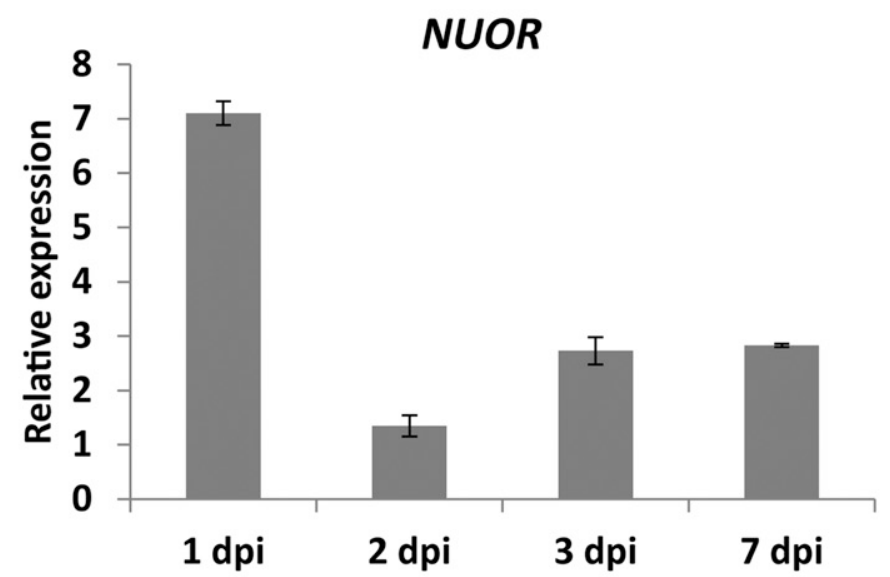

Fig. 1. Expression analysis of putative susceptibility genes (S-genes) in rice and tomato. Relative expression of A, OsIFR and B, OsNUOR in a Rhizoctonia solaniinfected rice cultivar (PB1). Relative expression of $\mathbf{C}, I F R$ and $\mathbf{D}, N U O R$ genes in tomato plants infected with $R$. solani. The expression of genes in infected samples (at different time points) was normalized with that of uninfected samples. Bars represent the mean value of three independent biological replicates. Error bars show the standard error of the mean. Os = Oryza sativa, $\mathrm{IFR}=$ isoflavone reductase and NUOR $=$ alternative NADH:ubiquinone oxidoreductase, and dpi $=$ days postinoculation. 
plants, whereas expression of other mitochondrial genes was not affected (Supplementary Fig. S3). The upregulation of these genes in silenced plants may compensate for the decrease in NUOR activity.

NUOR silencing modulates ROS accumulation during pathogenesis of $R$. solani in tomato. We also tested ROS accumulation in pTRV:NUOR and pTRV:0 tomato plants upon $R$. solani infection. Accumulation of localized ROS was observed around the infection site at $1 \mathrm{dpi}$ in pTRV:0 infiltrated leaves. Homogenous ROS accumulation (uniform brown coloration in the whole leaf) was observed in pTRV:NUOR leaves (Fig. 4B). Furthermore, ROS production was enhanced at 2 to 3 dpi, leading to the appearance of localized larger brown spots in infected pTRV: 0 leaves. Uniform brown coloration, along with a few small brown spots, was visible in $R$. solani-infected pTRV:NUOR leaves, suggesting homogenous ROS accumulation.

We also studied ROS accumulation at $7 \mathrm{dpi}$ of $R$. solani infection. The primary infected leaves were mostly disintegrated in both pTRV:0 and pTRV:NUOR infiltrated plants, so we analyzed ROS accumulation in other leaves of the twig. Most of the leaves showed dark brown spots attributable to DAB staining in the pTRV: 0 infiltrated plants, which correlated with necrotic disease lesions. However, uniform brown coloration was observed in the leaves of pTRV:NUOR plants, suggesting homogenous ROS accumulation (Fig. 4C). Taken together, this suggests that a preinduced ROS level in pTRV:NUOR plants may be associated with an induced defense response that controls $R$. solani infection.
Specific pathogenesis-related genes were induced in NUOR-silenced tomato upon $R$. solani infection. We dissected the expression of pathogenesis-related (PR) genes ( $P R 1, P R$ $P 2$, PR5, Nonexpressor of PR genes NP24 and NPR1) in pTRV: NUOR and pTRV:0 infiltrated tomato plants upon $R$. solani infection. Expression of $N P R I$ and $P R 5$ was significantly upregulated in pTRV:NUOR plants compared with pTRV:0 plants (Fig. 5). However, there was no significant difference in the expression of $P R 1, P R-P 2$, and NP24 in the infected pTRV:NUOR and pTRV:0 plants.

NUOR silencing alters host antioxidant expression and activity to suppress $R$. solani pathogenesis in tomato. We further assessed the expression and enzyme activity of some of the antioxidant genes in pTRV infiltrated plants upon $R$. solani infection at 3 dpi. Expression of CAT1, CAT2, Mn-SOD, APX1, and $A P X 2$ was upregulated in pTRV:NUOR infiltrated plants compared with pTRV:0 infiltrated plants (Fig. 6). Furthermore, enzyme activity of $C A T, S O D$, and $A P X$ was enhanced in pTRV: NUOR plants compared with pTRV:0 infiltrated plants (Fig. 7A to C). On the other hand, $\mathrm{H}_{2} \mathrm{O}_{2}$ content and MDA content (Fig. 7D and E) were relatively lower in pTRV:NUOR infiltrated plants compared with pTRV:0 infiltrated plants. However, only a marginal decrease in electrolyte leakage was observed in infected pTRV: NUOR plants compared with pTRV:0 plants (Fig. 7F).

Transient silencing of $O S N U O R$ confers tolerance against $\boldsymbol{R}$. solani infection in rice. To further substantiate NUOR as a potential S-gene, we assessed whether RNAi-mediated
A
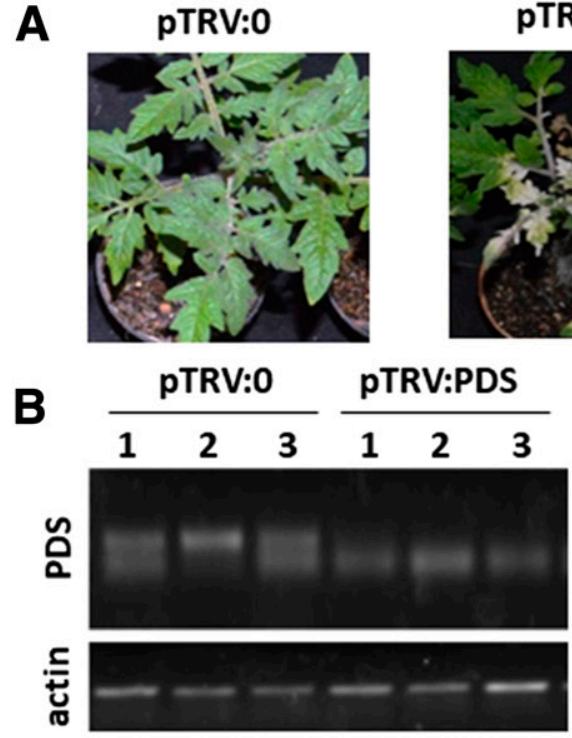

C

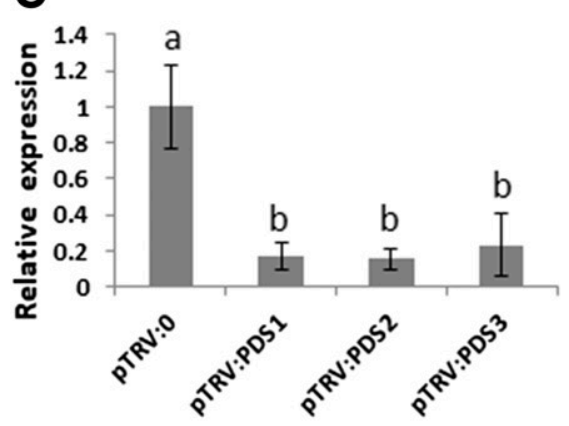

PTRV:PDS

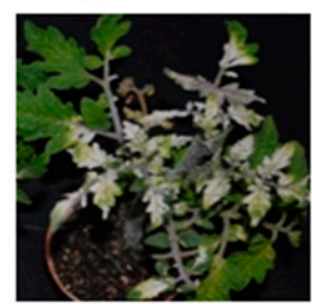

pTRV:IFR

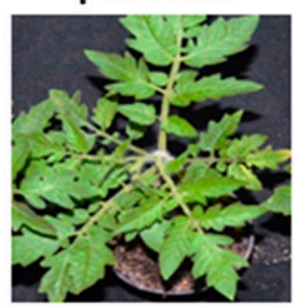

pTRV:IFR
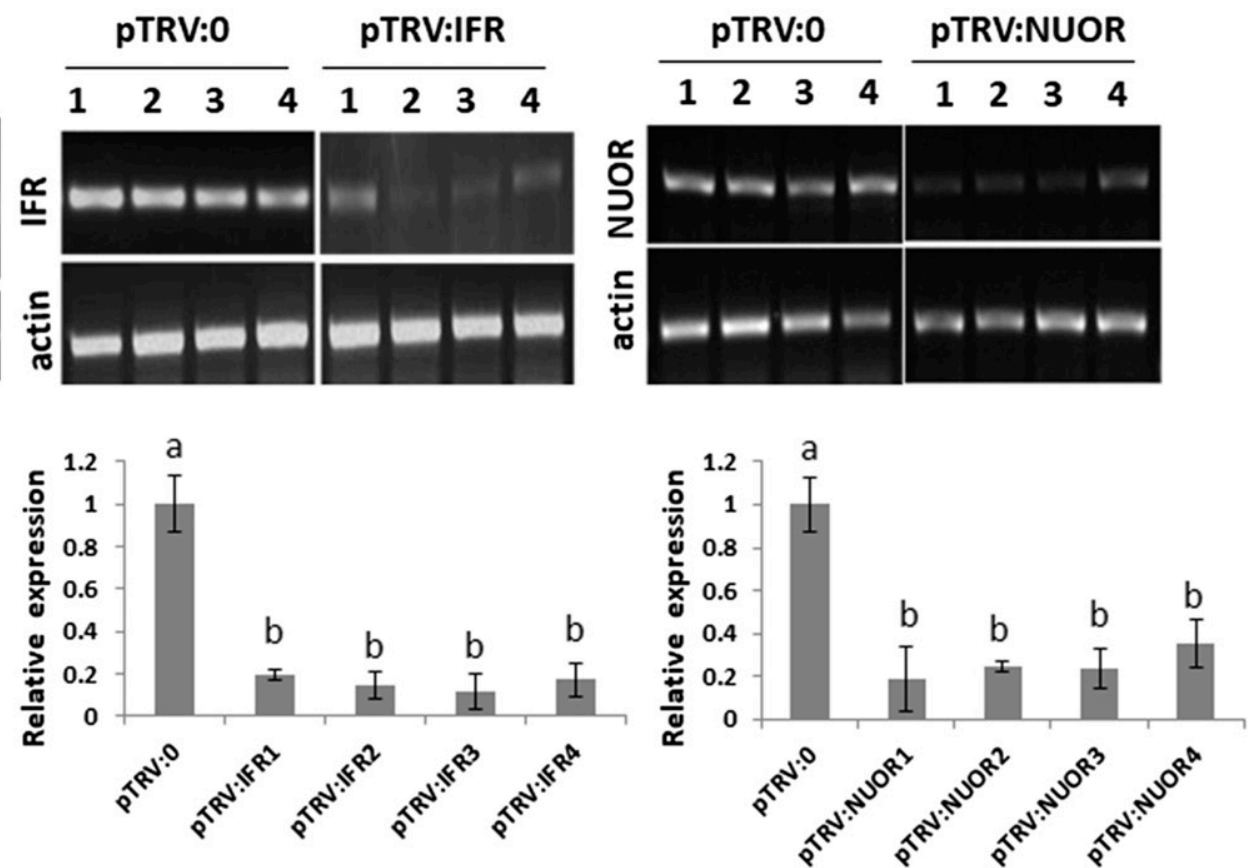

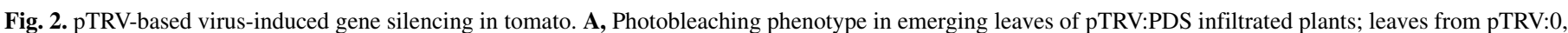

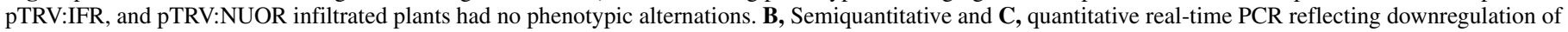

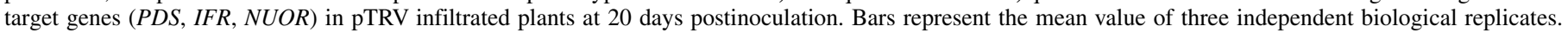

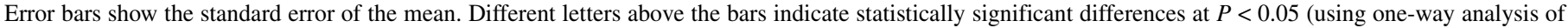
variance) TRV = Tobacco rattle virus, PDS = Phytoene desaturase, IFR = isoflavone reductase, and NUOR = alternative NADH:ubiquinone oxidoreductase. 
transient silencing of $O s N U O R$ provides tolerance against $R$. solani infections in rice. As shown in Supplementary Figure S4, the silenced rice plants (pBI121:hp-OsNUOR) showed relatively fewer disease symptoms compared with the empty vector (pBI121:0) infiltrated control plants. Furthermore, estimation of the disease index (in terms of RVSC) revealed a significant reduction in the pBI121:hp-OsNUOR plants compared with the pBI121:0 plants. DAB staining revealed large brown spots correlating with necrotic disease symptoms in pBI121:0 plants. However, relatively smaller brown necrotic spots were observed in pBI121:hp-OsNUOR plants. The homogenous induction of ROS in the uninfected pBI121:hpOsNUOR plants suggested that NUOR silencing enhances ROS accumulation in rice. In addition, we observed enhanced expression of various antioxidant genes (CATA, CATB, APX1, APX2, and $M n$ $S O D)$ in pBI121-OsNUOR plants compared with pBI121:0 plants upon $R$. solani infection.

\section{DISCUSSION}

Plants induce strong defense responses to protect themselves from pathogens. However, pathogens have evolved strategies to overcome host defense responses. Understanding how pathogens overcome host defense responses has long been of prime interest for plant pathologists. Studies suggest that some plant genes are hijacked by pathogens and are exploited as susceptibility factors to promote their pathogenesis (Lapin and Van den Ackerveken 2013; Mukhtar et al. 2011; Rodriguez-Moreno et al. 2018; Weßling et al. 2014). For example, silencing of S-genes enhanced resistance in transgenic potato plants against late blight disease caused by Phytophthora infestans (Sun et al. 2016). Similarly, silencing of grapevine susceptible genes provided resistance to powdery mildew disease (Pessina et al. 2016).

Our study provides evidence that NUOR (an alternative oxidoreductase) functions as a potential S-gene to promote $R$. solani infection in rice and tomato. NUOR functions as a mitochondrial component and is involved in the ETC pathway. It has been anticipated that downregulation of NUOR expression or mutation in NUOR may disturb the coordinated signaling cascade in the ETC pathway (Cvetkovska et al. 2014). Because mitochondrial components regulate constant ROS production, it was hypothesized that downregulation of NUOR expression may also modulate ROS production (Cvetkovska and Vanlerberghe 2012). A previous study revealed that silencing of alternative oxidases could enhance the production of ROS and reactive nitrogen species in tobacco plants
A
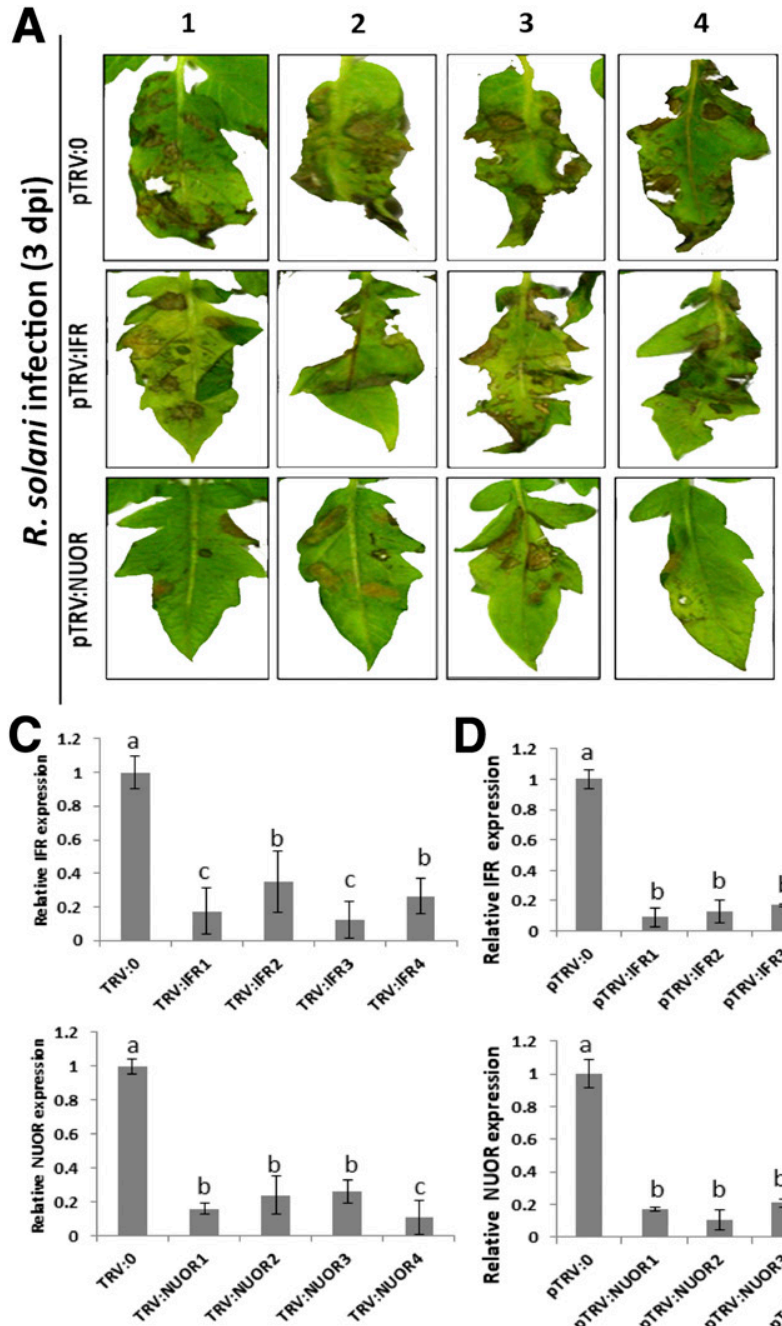
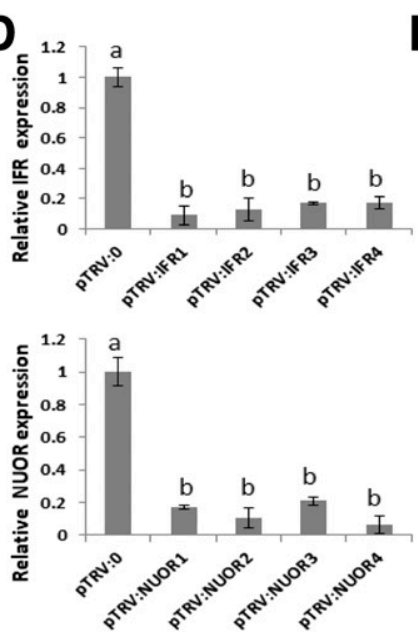

B

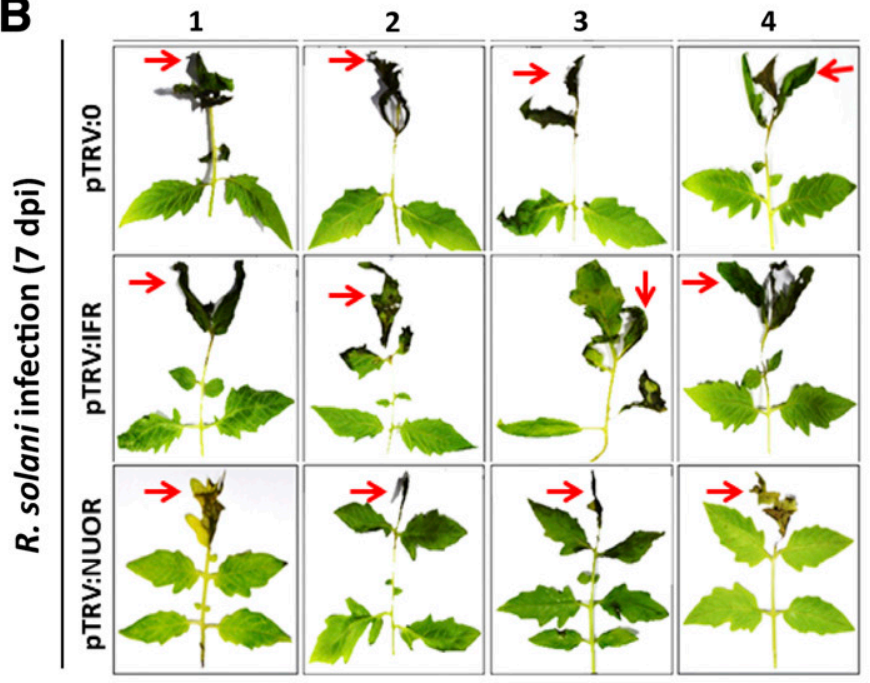

E
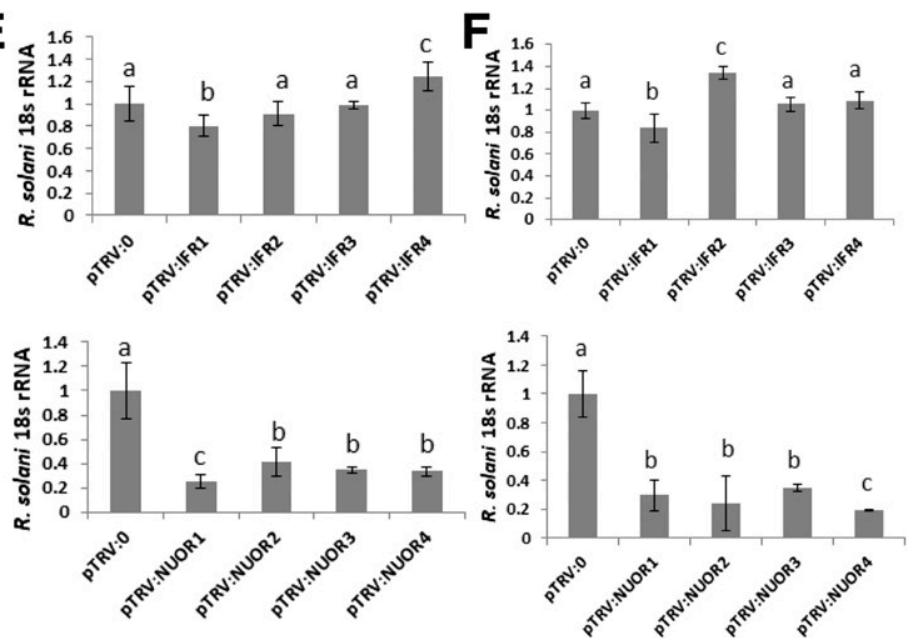

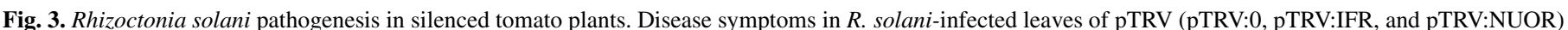

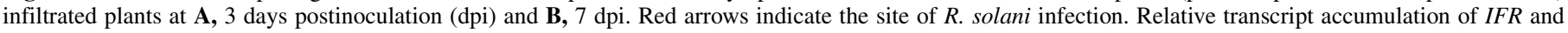

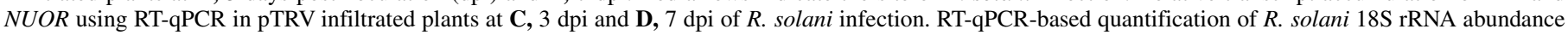

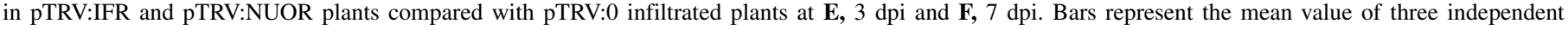

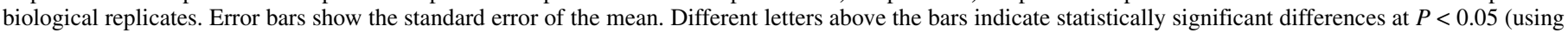

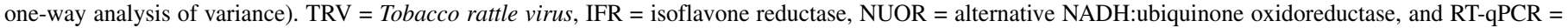
quantitative reverse transcription PCR. 
(Cvetkovska et al. 2014). In addition, benzothiadiazole-mediated inhibition of mitochondrial complex I enhanced ROS production (van der Merwe and Dubery 2006). In the present study, we observed homogeneous production of ROS being induced upon
NUOR silencing in tomato leaves. In addition, the silenced plants exhibited tolerance to $R$. solani infection, as we observed reduced disease symptoms as well as pathogen load in the infected tissues (Fig. 3).
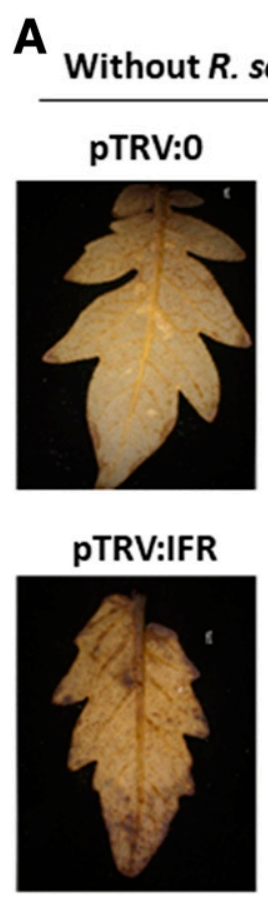

B

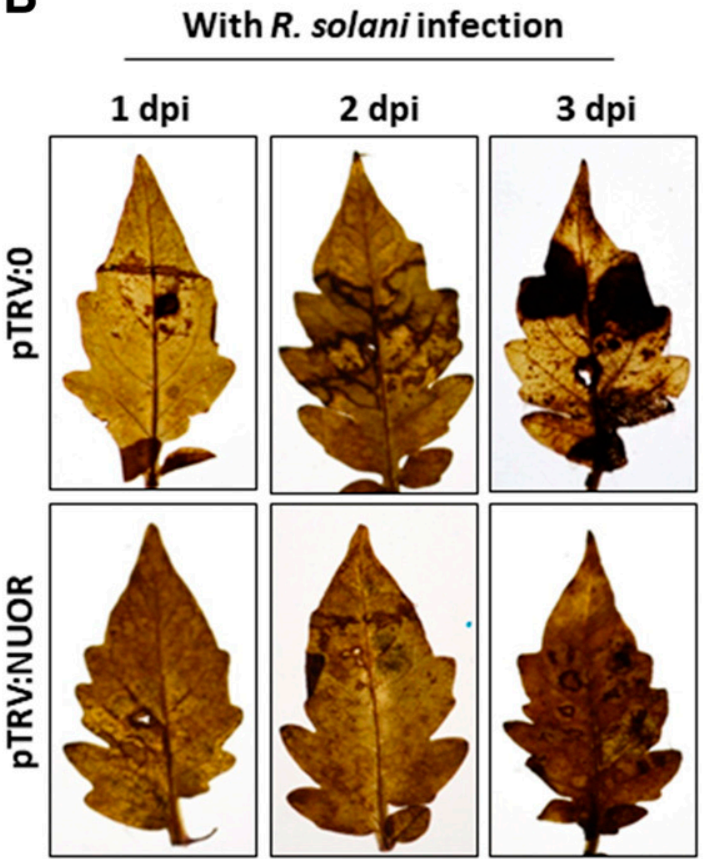

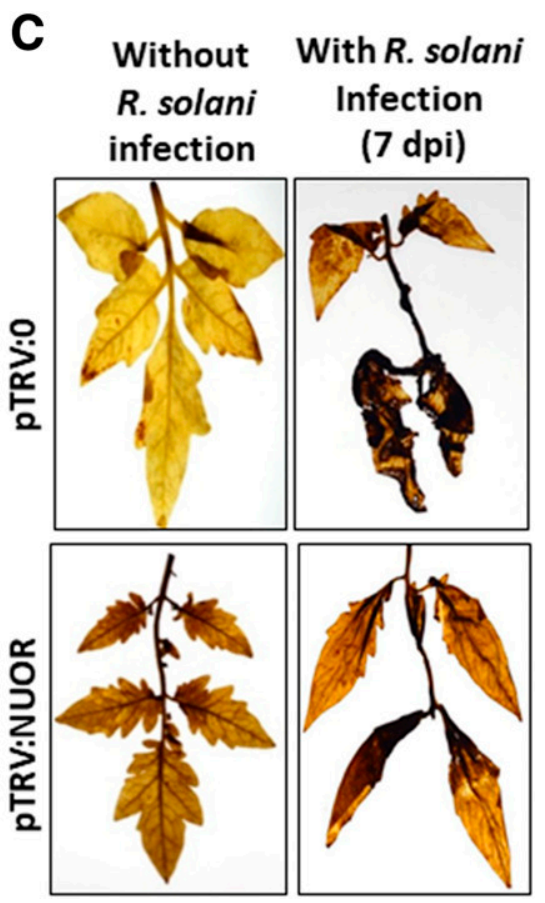

Fig. 4. 3,3'-Diaminobenzidine staining reflecting ROS accumulation in silenced tomato plants. A, ROS accumulation in emerging leaves of pTRV infiltrated plants (pTRV:0, pTRV:PDS, pTRV:IFR, pTRV:NUOR) at 20 days postinoculation (dpi). B, ROS accumulation in leaves of pTRV:0 and pTRV:NUOR infiltrated plants infected with Rhizoctonia solani at 1, 2, and 3 dpi. C, ROS accumulation in leaves of pTRV:0 and pTRV:NUOR infiltrated tomato plants infected with $R$. solani at 7 dpi. $\mathrm{ROS}=$ reactive oxygen species, TRV = Tobacco rattle virus, $\mathrm{PDS}=$ phytoene desaturase, IFR $=$ isoflavone reductase, and NUOR $=$ alternative NADH: ubiquinone oxidoreductase.

PR1

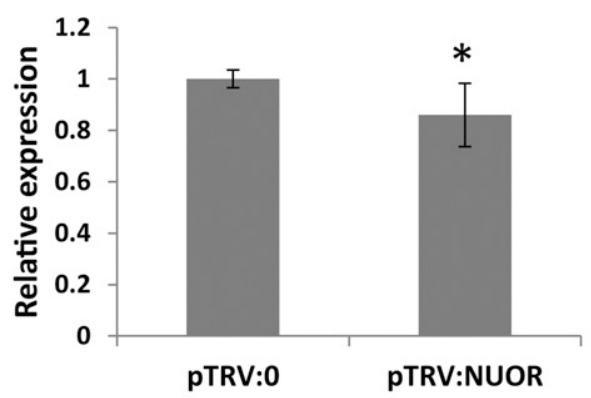

NPR1

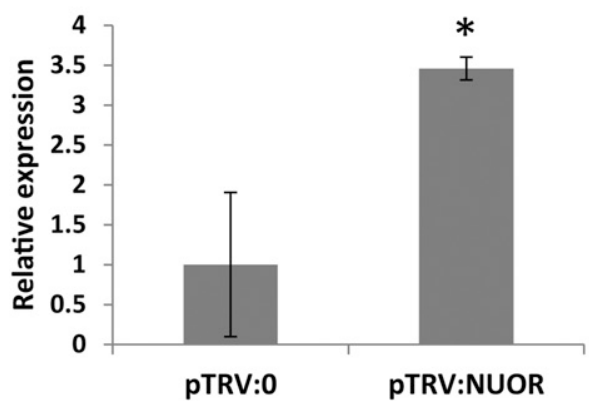

PR-P2

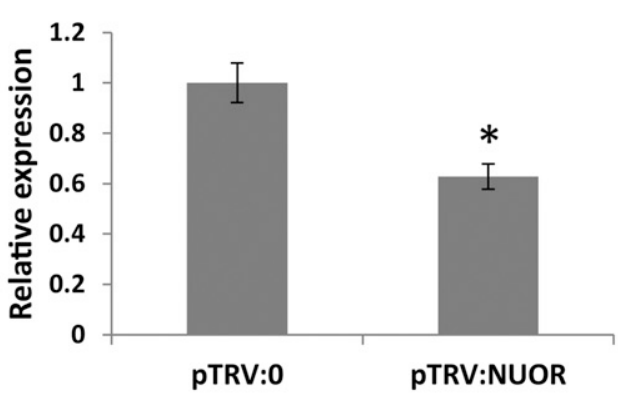

PR5

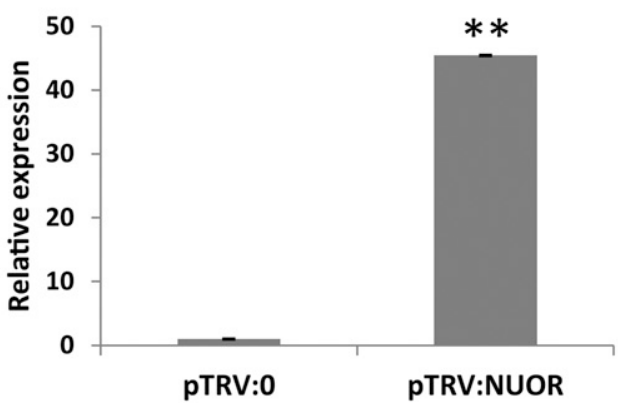

NP24

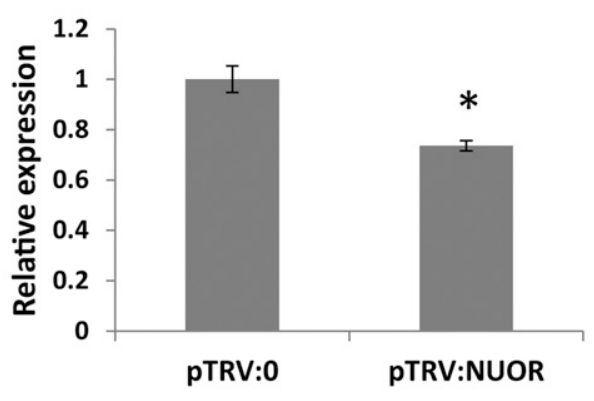

Fig. 5. Expression analysis of different pathogenesis-related $(P R)$ genes in pTRV infiltrated tomato plants upon Rhizoctonia solani infections at 3 days postinoculation. Bars represent the mean value of three independent biological replicates. Error bars show the standard error of the mean. $* P<0.05$ and $* * P<0.01$ (statistically significant differences using the Student $t$ test). TRV $=$ Tobacco rattle virus, NUOR $=$ alternative NADH:ubiquinone oxidoreductase, and $N P=$ nonexpressor of PR genes. 
$R$. solani infection leads to enhanced ROS production, which is helpful for the pathogen to cause necrosis in the infected plants (Ghosh et al. 2017; Torres et al. 2006). Similarly, we observed enhanced ROS accumulation localized surrounding the disease lesion in the infected
pTRV:0 plants (Fig. 5). However, ROS accumulation remained homogeneous upon $R$. solani infection in pTRV:NUOR plants. The antioxidant enzymes such as $C A T, S O D$, and $A P X$ were also induced in $R$. solani-infected pTRV:NUOR plants compared with pTRV:0 plants.
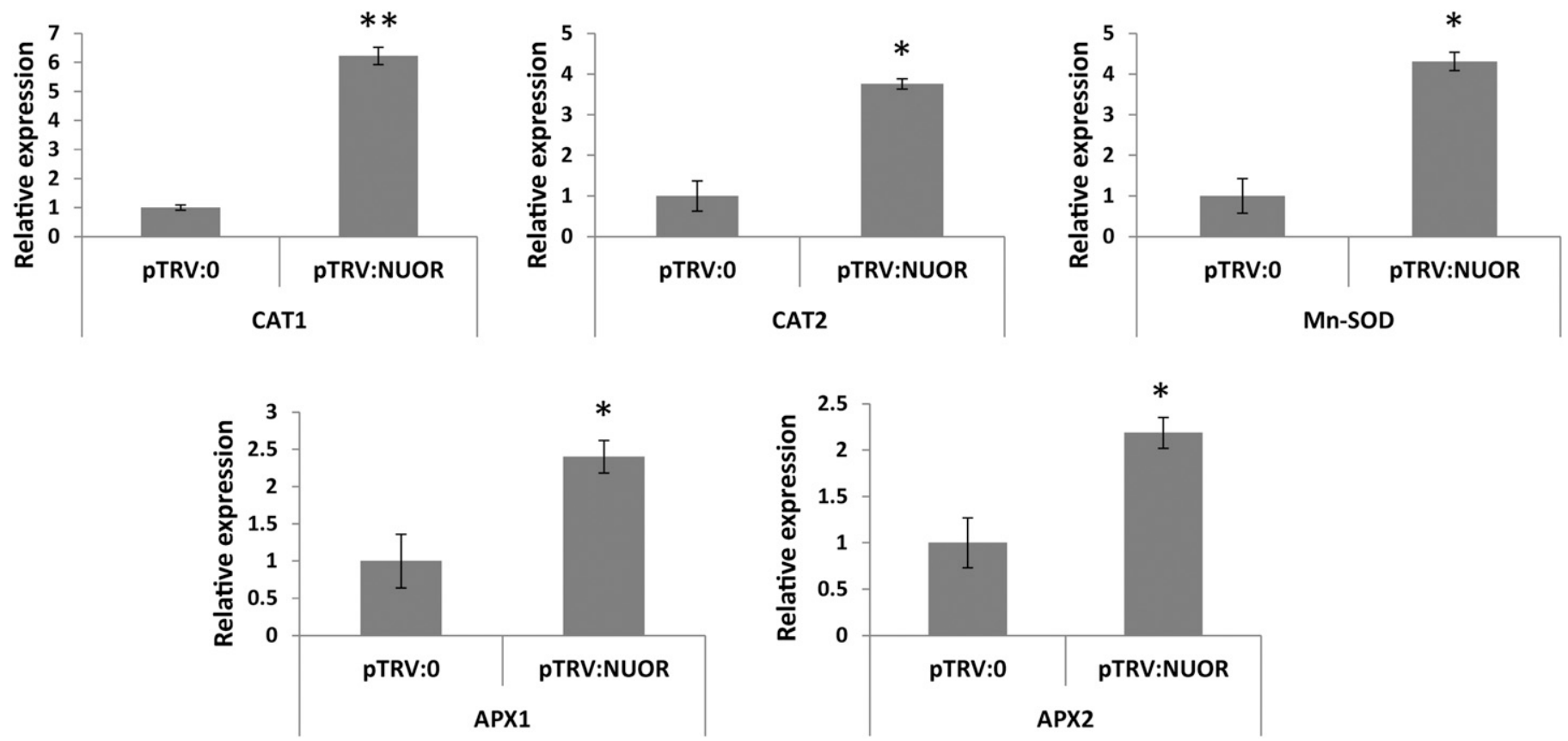

Fig. 6. Expression analysis of antioxidant genes in pTRV infiltrated tomato plants upon Rhizoctonia solani infection at 3 days postinoculation. Bars represent the mean value of three independent biological replicates. Error bars show the standard error of the mean. $* P<0.05$ and $* * P<0.01$ (statistically significant differences using the Student $t$ test $)$ TRV $=$ Tobacco rattle virus, NUOR $=$ alternative $\mathrm{NADH}$ :ubiquinone oxidoreductase, $\mathrm{CAT}=$ catalase, $\mathrm{SOD}=$ superoxide dismutase, and $\mathrm{APX}=$ ascorbate peroxidase.
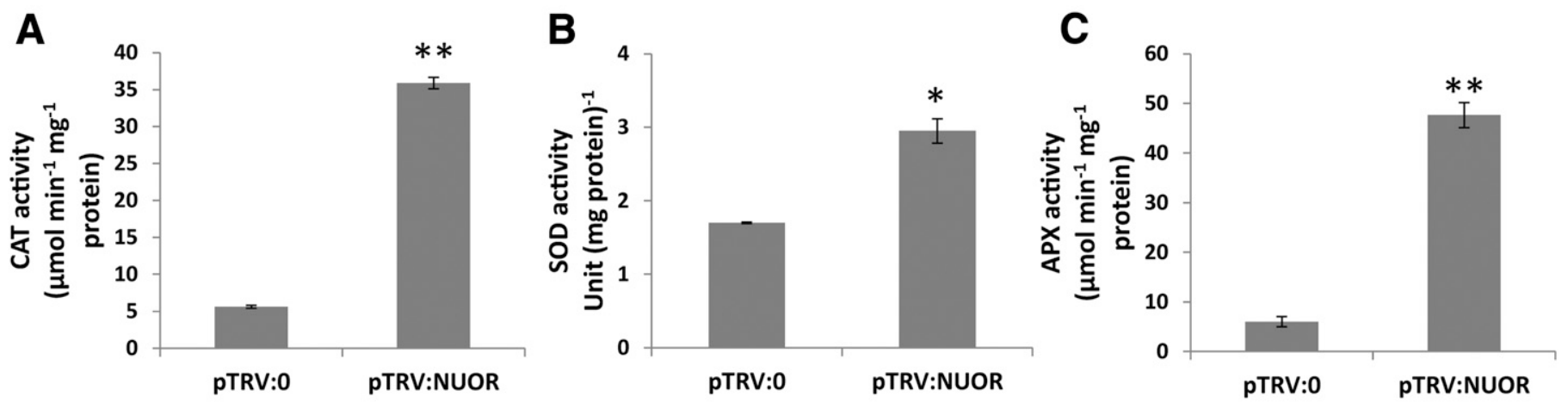

D

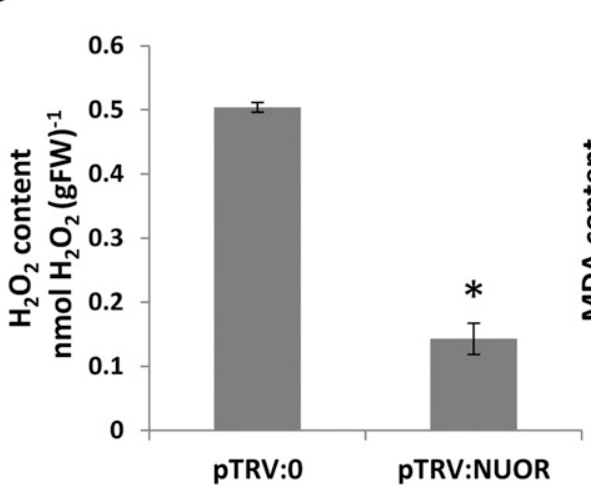

$\mathbf{E}$

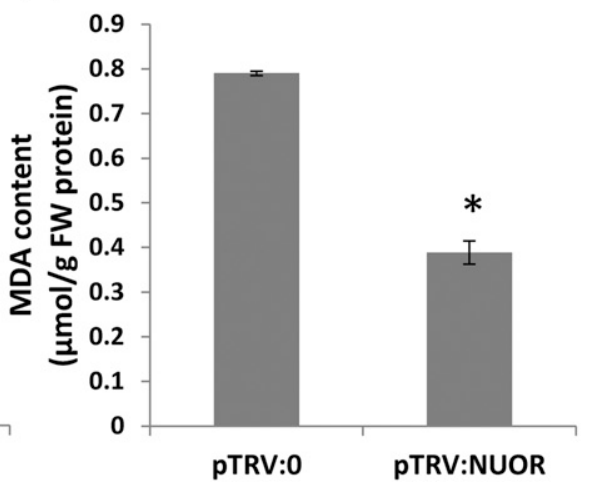

$\mathbf{F}$

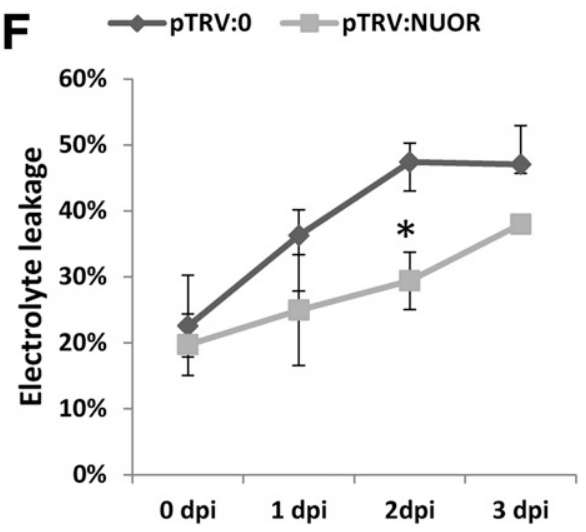

Fig. 7. NUOR-silenced tomato plants demonstrate higher proficiency in managing oxidative stress during Rhizoctonia solani infection. A, B, and C, Antioxidant enzyme (CAT, SOD, $A P X)$ activity at 3 days postinoculation (dpi), D, $\mathrm{H}_{2} \mathrm{O}_{2}$ content at 3 dpi, $\mathbf{E}$, MDA content at 3 dpi, and $\mathbf{F}$, electrolyte leakage at 1, 2, and 3 dpi in $R$. solani-infected tomato plants. Bars represent the mean value of three independent biological replicates. Error bars show the standard error of the mean. $* P<$ 0.05 and ${ }^{*} * P<0.01$ (statistically significant differences using the Student $t$ test). CAT $=$ catalase, TRV $=$ Tobacco rattle virus, NUOR $=$ alternative NADH: ubiquinone oxidoreductase, $\mathrm{SOD}=$ superoxide dismutase, $\mathrm{APX}=$ ascorbate peroxidase, and MDA = malondialdehyde. 
Overall, this suggested that antioxidant machinery is induced upon NUOR silencing, which may prevent the pathogen-induced ROS burst. This tempts us to speculate that NUOR silencing induces an optimal level of ROS, which in turn may be helpful for inducing defense responses. Previous reports suggested that an increase in ROS level is associated with an enhanced defense response that serves as a barrier for fungal infection (Ali et al. 2018; Cvetkovska et al. 2014; Lamb and Dixon 1997; Tripathy and Oelmüller 2012). A decrease in $\mathrm{H}_{2} \mathrm{O}_{2}$ content, MDA content, and electrolyte leakage in $R$. solani-infected $N U O R$-silenced plants was quite noteworthy in this study. Previous studies suggested that decreases in $\mathrm{H}_{2} \mathrm{O}_{2}$ content, MDA content, and electrolyte leakage are associated with an induced defense response upon pathogen attack (Bundó and Coca 2017; Liu et al. 2013). Taken together, this suggested that the optimal level of ROS in NUORsilenced plants potentially induces a defense response during $R$. solani infection. This was further supported by our observation that two host defense marker genes, NPRI and PR5 (Ali et al. 2017; El-kereamy et al. 2011; Şestacova et al. 2016), were upregulated in NUOR-silenced plants upon $R$. solani infection.

Although $R$. solani is a necrotrophic pathogen, it is speculated that $R$. solani adopts a brief biotrophic phase before entering into the necrotrophic phase for nutrient acquisition and pathogenesis (Ghosh et al. 2017). Therefore, it appears that the optimal ROSinduced defense response in NUOR-silenced plants may suppress $R$. solani colonization in the biotrophic phase, and thereby delays its transition to the necrotrophic phase. Because NUOR is widely conserved in plants, the ability to manipulate its expression may serve as one of the reasons for the widespread success of $R$. solani as a phytopathogen. However, how $R$. solani manipulates host NUOR during pathogenesis remains to be elucidated in future research.

\section{ACKNOWLEDGMENTS}

We thank Muthappa Senthil-Kumar (National Institute of Plant Genome Research, New Delhi, India) for providing the pTRV (pTRV1+pTRV2) plasmids. We also acknowledge assistance from the National Institute of Plant Genome Research central instrumentation facilities.

\section{LITERATURE CITED}

Ali, M., Cheng, Z., Ahmad, H., and Hayat, S. 2018. Reactive oxygen species (ROS) as defenses against a broad range of plant fungal infections and case study on ROS employed by crops against Verticillium dahliae wilts. J. Plant Interact. 13:353-363.

Ali, S., Mir, Z. A., Tyagi, A., Mehari, H., Meena, R. P., Bhat, J. A., Yadav, P., Papalou, P., Rawat, S., and Grover, A. 2017. Overexpression of NPR1 in Brassica juncea confers broad spectrum resistance to fungal pathogens. Front. Plant Sci. 8:1693.

Anderson, J. P., Sperschneider, J., Win, J., Kidd, B., Yoshida, K., Hane, J., Saunders, D. G. O., and Singh, K. B. 2017. Comparative secretome analysis of Rhizoctonia solani isolates with different host ranges reveals unique secretomes and cell death inducing effectors. Sci. Rep. 7:10410.

Azevedo, R. A., Alas, R. M., Smith, R. J., and Lea, P. J. 1998. Response of antioxidant enzymes to transfer from elevated carbon dioxide to air and ozone fumigation, in the leaves and roots of wild-type and a catalasedeficient mutant of barley. Physiol. Plant. 104:280-292.

Benedito, V. A., Visser, P. B., Angenent, G. C., and Krens, F. A. 2004. The potential of virus-induced gene silencing for speeding up functional characterization of plant genes. Genet. Mol. Res. 3:323-341.

Bundó, M., and Coca, M. 2017. Calcium-dependent protein kinase OsCPK10 mediates both drought tolerance and blast disease resistance in rice plants. J. Exp. Bot. 68:2963-2975.

Channamallikarjuna, V., Sonah, H., Prasad, M., Rao, G. J. N., Chand, S., Upreti, H. C., Singh, N., and Sharma, T. 2009. Identification of major quantitative trait loci qSBR11-1 for sheath blight resistance in rice. Mol. Breed. 25:155-166.

Cheng, Q., Li, N., Dong, L., Zhang, D., Fan, S., Jiang, L., Wang, X., Xu, P., and Zhang, S. 2015. Overexpression of soybean isoflavone reductase (GmIFR) enhances resistance to Phytophthora sojae in soybean. Front. Plant Sci. 6: 1024.

Cvetkovska, M., Dahal, K., Alber, N. A., Jin, C., Cheung, M., and Vanlerberghe, G. C. 2014. Knockdown of mitochondrial alternative oxidase induces the 'stress state' of signaling molecule pools in Nicotiana tabacum, with implications for stomatal function. New Phytol. 203:449-461.

Cvetkovska, M., and Vanlerberghe, G. C. 2012. Alternative oxidase modulates leaf mitochondrial concentrations of superoxide and nitric oxide. New Phytol. 195:32-39.

Dobón, A., Canet, J. V., García-Andrade, J., Angulo, C., Neumetzler, L., Persson, S., and Vera, P. 2015. Novel disease susceptibility factors for fungal necrotrophic pathogens in Arabidopsis. PLoS Pathog 11: e 1004800 .

El-kereamy, A., El-sharkawy, I., Ramamoorthy, R., Taheri, A., Errampalli, D., Kumar, P., and Jayasankar, S. 2011. Prunus domestica pathogenesis-related protein-5 activates the defense response pathway and enhances the resistance to fungal infection. PLoS One 6:e17973.

Engelhardt, S., Stam, R., and Hückelhoven, R. 2018. Good riddance? Breaking disease susceptibility in the era of new breeding technologies. Agronomy (Basel) 8:114.

Ghosh, S., Gupta, S. K., and Jha, G. 2014. Identification and functional analysis of AG1 IA specific genes of Rhizoctonia solani. Curr. Genet. 60: 327-341.

Ghosh, S., Kanwar, P., and Jha, G. 2017. Alterations in rice chloroplast integrity, photosynthesis and metabolome associated with pathogenesis of Rhizoctonia solani. Sci. Rep. 7:41610.

Ghosh, S., Mirza, N., Kanwar, P., Tyagi, K., and Jha, G. 2019. Genome analysis provides insight about pathogenesis of Indian strains of Rhizoctonia solani in rice. Funct. Integr. Genomics. doi:10.1007/s10142-01900687-y

Giannopolitis, C. N., and Ries, S. K. 1977. Superoxide dismutases: I. Occurrence in higher plants. Plant Physiol. 59:309-314.

Hodges, D. M., DeLong, J. M., Forney, C. F., and Prange, R. K. 1999. Improving the thiobarbituric acid-reactive-substances assay for estimating lipid peroxidation in plant tissues containing anthocyanin and other interfering compounds. Planta 207:604-611.

Hok, S., Danchin, E. G. J., Allasia, V., Panabières, F., Attard, A., and Keller, H. 2011. An Arabidopsis (malectin-like) leucine-rich repeat receptor-like kinase contributes to downy mildew disease. Plant Cell Environ. 34: 1944-1957.

Jha, G., Rajeshwari, R., and Sonti, R. V. 2007. Functional interplay between two Xanthomonas oryzae pv. oryzae secretion systems in modulating virulence on rice. Mol. Plant-Microbe Interact. 20:31-40.

Jones, J. D., and Dangl, J. L. 2006. The plant immune system. Nature 444: 323-329.

Kang, N. J., Kang, Y. I., Kang, K. H., and Jeong, B. R. 2009. Induction of thermotolerance and activation of antioxidant enzymes in $\mathrm{H}_{2} \mathrm{O}_{2}$ pre-applied leaves of cucumber and tomato seedlings. J. Jpn. Soc. Hortic. Sci. 78: 320-329.

Kerscher, S. J. 2000. Diversity and origin of alternative NADH:ubiquinone oxidoreductases. Biochim. Biophys. Acta Bioenergetics 1459:274-283.

Kim, S. G., Kim, S. T., Wang, Y. M., Kim, S. K., Lee, C. H., Kim, K. K., Kim, J. K., Lee, S. Y., and Kang, K. Y. 2010. Overexpression of rice isoflavone reductase-like gene $(O S I R L)$ confers tolerance to reactive oxygen species. Physiol. Plant. 138:1-9.

Kuramae, E. E., Buzeto, A. L., Ciampi, M. B., and Souza, N. L. 2003. Identification of Rhizoctonia solani AG 1-IB in lettuce, AG 4 HG-I in tomato and melon, and AG 4 HG-III in broccoli and spinach, in Brazil. Eur. J. Plant Pathol. 109:391-395.

Kusch, S., and Panstruga, R. 2017. mlo-based resistance: An apparently universal "weapon" to defeat powdery mildew disease. Mol. Plant-Microbe Interact. 30:179-189.

Lamb, D., and Dixon, R. A. 1997. The oxidative burst in plant disease resistance. Annu. Rev. Plant Physiol. Plant Mol. Biol. 48:251-275.

Lapin, D., and Van den Ackerveken, G. 2013. Susceptibility to plant disease: More than a failure of host immunity. Trends Plant Sci. 18:546-554.

Liu, J., Macarisin, D., Wisniewski, M., Sui, Y., Droby, S., Norelli, J., and Hershkovitz, V. 2013. Production of hydrogen peroxide and expression of ROS-generating genes in peach flower petals in response to host and nonhost fungal pathogens. Plant Pathol. 62:820-828.

Liu, Y., Schiff, M., and Dinesh-Kumar, S. P. 2002. Virus-induced gene silencing in tomato. Plant J. 31:777-786.

Livak, K. J., and Schmittgen, T. D. 2001. Analysis of relative gene expression data using real-time quantitative PCR and the 2(-delta delta $\mathrm{C}(\mathrm{T})$ ) method. Methods 25:402-408.

Meyer, E. H., Tomaz, T., Carroll, A. J., Estavillo, G., Delannoy, E., Tanz, S. K., Small, I. D., Pogson, B. J., and Millar, A. H. 2009. Remodeled respiration in ndufs4 with low phosphorylation efficiency suppresses Arabidopsis germination and growth and alters control of metabolism at night. Plant Physiol. 151:603-619.

Misawa, T., and Kuninaga, S. 2010. The first report of tomato foot rot caused by Rhizoctonia solani AG-3 PT and AG-2-Nt and its host range and molecular characterization. J. Gen. Plant Pathol. 76:310-319. 
Møller, I. M. 2001. Plant mitochondria and oxidative stress: Electron transport, NADPH turnover, and metabolism of reactive oxygen species. Annu. Rev. Plant Physiol. Plant Mol. Biol. 52:561-591.

Mukhtar, M. S., Carvunis, A. R., Dreze, M., Epple, P., Steinbrenner, J., Moore, J., Tasan, M., Galli, M., Hao, T., Nishimura, M. T., Pevzner, S. J., Donovan, S. E., Ghamsari, L., Santhanam, B., Romero, V., Poulin, M. M., Gebreab, F., Gutierrez, B. J., Tam, S., Monachello, D., Boxem, M., Harbort, C. J., McDonald, N., Gai, L., Chen, H., He, Y., European Union Effectoromics Consortium, Vandenhaute, J., Roth, F. P., Hill, D. E., Ecker, J. R., Vidal, M., Beynon, J., Braun, P., and Dangl, J. L. 2011. Independently evolved virulence effectors converge onto hubs in a plant immune system network. Science 333:596-601.

Nakano, Y., and Asada, K. 1981. Hydrogen peroxide is scavenged by ascorbate specific peroxidase in spinach chloroplasts. Plant Cell Physiol. 22:867-880.

Pan, X. B., Rush, M. C., Sha, X. Y., Xie, Q. J., Liscombe, S. D., Stenina, S. R., and Orad, J. H. 1999. Major gene non-allelic sheath blight resistance from the rice cultivars Jasmine 85 and Teqing. Crop Sci. 39:338-346.

Pessina, S., Lenzi, L., Perazzolli, M., Campa, M., Costa, L. D., Urso, S., Vale, G., Salamini, F., Velasco, R., and Malnoy, M. 2016. Knockdown of MLO genes reduces susceptibility to powdery mildew in grapevine. Hortic. Res. 3:16016.

Quijano, C., Trujillo, M., Castro, L., and Trostchansky, A. 2016. Interplay between oxidant species and energy metabolism. Redox Biol. 8:28-42.

Rodriguez-Moreno, L., Ebert, M. K., Bolton, M. D., and Thomma, P. B. H. J. 2018. Tools of the crook- infection strategies of fungal plant pathogens. Plant J. 93:664-674.

Saha, B., Borovskii, G., and Panda, S. K. 2016. Alternative oxidase and plant stress tolerance. Plant Signal. Behav. 11:e1256530.

Santos, C., Duarte, S., Tedesco, S., Fevereiro, P., and Costa, R. L. 2017. Expression profiling of Castanea genes during resistant and susceptible interactions with the oomycete pathogen Phytophthora cinnamomi reveal possible mechanisms of immunity. Front. Plant Sci. 8:515.

Schertl, P., and Braun, H. P. 2014. Respiratory electron transfer pathways in plant mitochondria. Front. Plant Sci. 5:163.

Schmittgen, T. D., and Livak, K. J. 2008. Analyzing real-time PCR data by the comparative C(T) method. Nat. Protoc. 3:1101-1108.

Schnepf, V., Vlot, A. C., Kugler, K., and Hückelhoven, R. 2018. Barley susceptibility factor RACB modulates transcript levels of signalling protein genes in compatible interaction with Blumeria graminis f.sp. hordei. Mol. Plant Pathol. 19:393-404.

Scofield, S. R., and Nelson, R. S. 2009. Resources for virus-induced gene silencing in the grasses. Plant Physiol. 149:152-157.

Senthil-Kumar, M., and Mysore, K. S. 2011. New dimensions for VIGS in plant functional genomics. Trends Plant Sci. 16:656-665.

Senthil-Kumar, M., and Mysore, K. S. 2014. Tobacco rattle virus-based virusinduced gene silencing in Nicotiana benthamiana. Nat. Protoc. 9: $1549-1562$.
Sestacova, T., Giscă, I., Cucereavîi, A., Port, A., and Duca, M. 2016. Expression of defence-related genes in sunflower infected with broomrape. Biotechnol. Biotechnol. Equip. 30:685-691.

Soto, D., Córdoba, J. P., Villarreal, F., Bartoli, C., Schmitz, J., Maurino, V. G., Braun, H. P., Pagnussat, G. C., and Zabaleta, E. 2015. Functional characterization of mutants affected in the carbonic anhydrase domain of the respiratory complex I in Arabidopsis thaliana. Plant J. 83:831-844.

Srinivasachary, L., Willocquet, L., and Savary, S. 2011. Resistance to rice sheath blight (Rhizoctonia solani Kühn) [(teleomorph: Thanatephorus cucumeris (A.B. Frank) Donk.] disease: Current status and perspectives. Euphytica 178:1-22.

Sun, K., Wolters, A. M., Vossen, J. H., Rouwet, M. E., Loonen, A. E., Jacobsen, E., Visser, R. G., and Bai, Y. 2016. Silencing of six susceptibility genes results in potato late blight resistance. Transgenic Res. 25:731-742.

Taheri, P., and Tarighi, S. 2012. The role of pathogenesis related proteins in the tomato-Rhizoctonia solani interaction. J. Bot. 7:1-6.

Torres, M. A., Jones, J. D. G., and Dangl, J. L. 2006. Reactive oxygen species signaling in response to pathogens. Plant Physiol. 141:373-378.

Tripathy, B. C., and Oelmüller, R. 2012. Reactive oxygen species generation and signaling in plants. Plant Signal. Behav. 7:1621-1633.

van der Merwe, J. A., and Dubery, I. A. 2006. Benzothiadiazole inhibits mitochondrial NADH: ubiquinone oxidoreductase in tobacco. J. Plant Physiol. 163:877-882.

Velikova, V., Yordanov, I., and Edreva, A. 2000. Oxidative stress and some antioxidant systems in acid rain-treated bean plants: Protective role of exogenous polyamines. Plant Sci. 151:59-66.

Weßling, R., Epple, P., Altmann, S., He, Y. J., Yang, L., Henz, S. R., McDonald, N., Wiley, K., Bader, K. C., Gläßer, C., Mukhtar, M. S., Haigis, S., Ghamsari, L., Stephens, A. E., Ecker, J. R., Vidal, M., Jones, J. D. G., Mayer, K. F. X., Ver Loren van Themaat, E., Weigel, D., Schulze-Lefert, P., Dangl, J. L., Panstruga, R., and Braun, P. 2014. Convergent targeting of a common host protein-network by pathogens effectors from three kingdoms of life. Cell Host Microbe 16:364-375.

Wu, J., Sun, Y., Zhao, Y., Zhang, J., Luo, L., Li, M., Wang, J., Yu, H., Liu, G., Yang, L., Xiong, G., Zhou, J. M., Zuo, J., Wang, Y., and Li, J. 2015. Deficient plastidic fatty acid synthesis triggers cell death by modulating mitochondrial reactive oxygen species. Cell Res. 25:621-633.

Xia, Y., Fei, B., He, J., Zhou, M., Zhang, D., Pan, L., Li, S., Liang, Y., Wang, L., Zhu, J., Li, P., and Zheng, A. 2017. Transcriptome analysis reveals the host selection fitness mechanisms of the Rhizoctonia solani AG1IA pathogen. Sci. Rep. 7:10120.

Zou, J. H., Pan, X. B., Chen, Z. X., Xu, J. Y., Lu, J. F., Zhai, W. X., and Zhu, L. H. 2000. Mapping quantitative trait loci controlling sheath blight resistance in two rice cultivars (Oryza sativa L.). Theor. Appl. Genet. 101: 569-573. 